\title{
Scientists, supporters rally in Canadian cities to support basic research
}

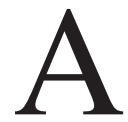

bout 200 scientists, students and supporters demonstrated in Ottawa, Ontario, joining others in major cities across Canada on Sept.17, calling for more funding for basic research and decrying the lack of evidence-based policy and transparent decision-making by the Conservative government.

"We're all here today because we know that science matters," Katie Gibbs, a biologist and one of the organizers of the Stand Up for Science rallies, told the crowd of demonstrators on Parliament Hill. "We know that good science, when it's coupled with good decision-making, is what keeps our air and water clean. It's what keeps us safe and healthy, and it's what keeps our economy growing strong."
In Ottawa, participants - many garbed in the stereotypical white lab coats that proclaimed their affiliation to science - held signs indicating they were protesting a grab bag of federal decisions. Those decisions include cuts to funding for basic research, the abandonment of federal research institutions such as the Experimental Lakes Area and prohibitions that prevent scientists employed in the federal civil service from conducting interviews or discussing their work without government permission.

"Let Scientists Speak - The Public Needs to Know" and "Canadians Want Evidence-Based Policy, Not Ideology" were among the slogans printed on placards, as well as the more lighthearted "Scientists Do It with Models."
One sign, wielded by a man in a lab coat with a telescope glued to his hard hat, read "Desperately Searching for Intelligent Life on Parliament Hill."

After a similar protest last year, Gibbs and other participants began a new organization called Evidence for Democracy. The organization is gathering a petition and organizing a letterwriting campaign to members of Parliament to mobilize Canadians to demand science-informed decision-making.

"We're nonpartisan, science-led, and we're advocating for the transparent use of evidence in decisionmaking," said Gibbs. As she spoke, simultaneous protests were going on in Vancouver, British Columbia; Winnipeg, Manitoba; Halifax, Nova Scotia; Edmonton, Alberta; Yellowknife,

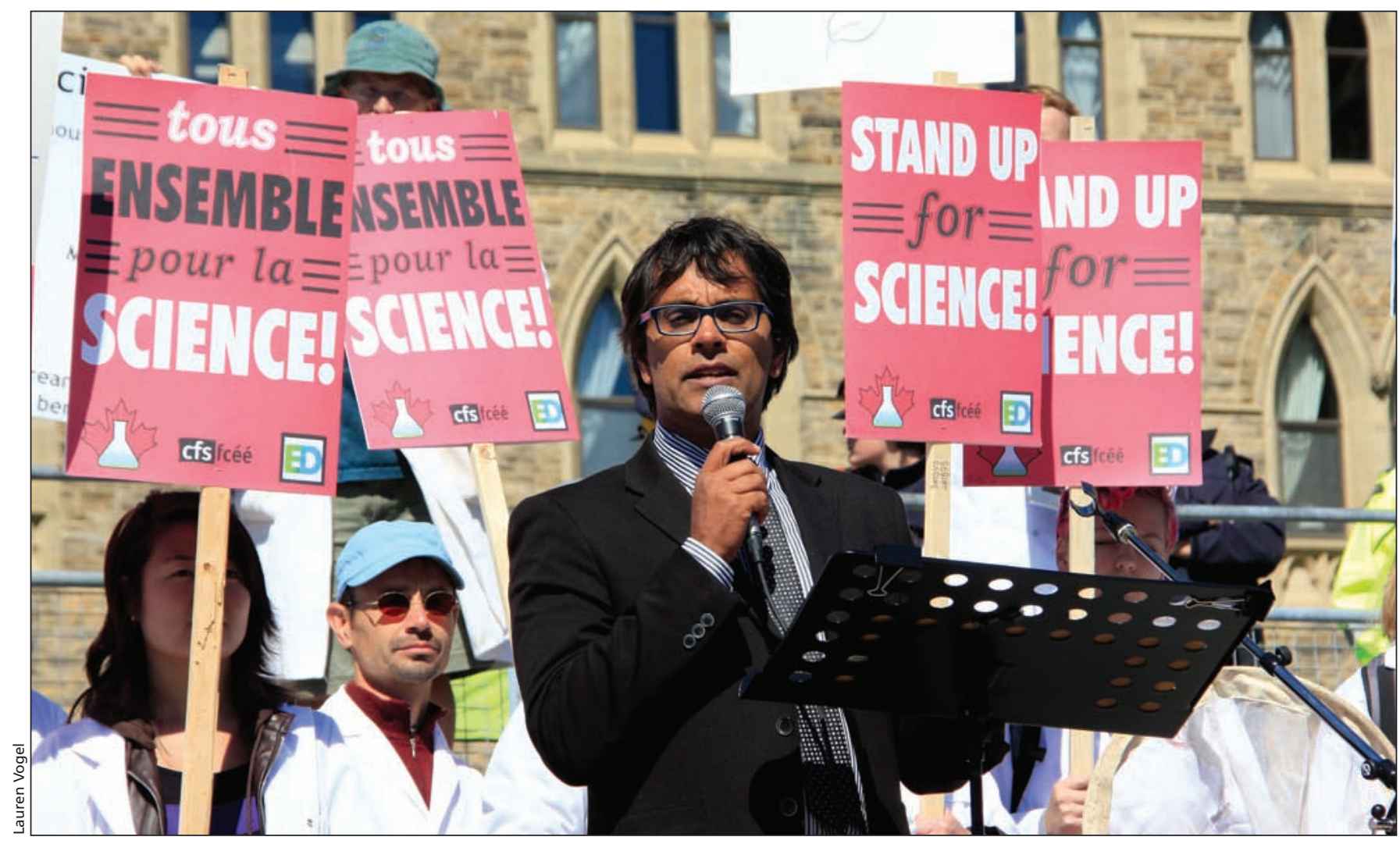

Dr. Kapil Khatter, a family physician at the University of Ottawa, Ontario, joined scientists across Canada in calling for more federal funding for basic research and evidence-based public policy. 
Northwest Territories; Toronto, Ontario; Montréal, Quebec; Fredericton, New Brunswick and other cities.

Increasingly, the government is funding research through funds or grants to programs and agencies that specify industrial partnerships or are directed at solving applied research problems or at increasing innovation and commercialization, a change in direction that comes at the expense of creativity-driven research, said several university professors at the Ottawa rally.

They pointed to a shift in the National Research Council (NRC)'s mandate, for example The NRC received \$121 million in new money in the 2013 federal budget, but the storied institution now focuses on providing companies with access to specialized labs, testing facilities and technical services. Additional federal money also went to the NRC's Industrial Research Assistance Program, which provides assistance to improve innovation at small and medium-sized businesses.

Previously, the NRC was led or was home to scientists of international repute and produced ground-breaking discoveries, Béla Joós, a physics professor at the University of Ottawa, told the demonstrators. Ten Nobel prize-winning scientists have been associated with the NRC in the past. By 2012, its output of peer-reviewed papers had shrunk to 436, from 1991 in 2000, and its application for patents had shrunk to 3 from 53 .

"Transformational changes come from basic science," Joós said, to applause from the crowd. "Now, we're being told what to work on. I don't want to prostitute myself for a few little jobs for industry."

Dr. Kapil Khatter, an Ottawa family doctor, spoke at the demonstration to remind people that many of the innovations the health care system relies on, such as magnetic resonance imaging, came from basic science. "Public funding of public science is essential," Khatter said. "It's public science that told us asbestos was harming workers when the asbestos industry was telling us it was fine," he added, citing similar examples concerning the harm flowing from lead in gasoline and the cancer-causing peril of cigarettes despite assurances to the contrary from the tobacco industry.

"Canadians want their health care practitioners to have the best possible evidence to make decisions with," Khatter said. "We're not saying scientists should speak for government - we're just saying scientists should be able to speak to their own science."

Scientists who work for the federal government are still being intimidated into keeping silent about their research, said Gary Corbett, president and CEO of the Professional Institute of the Public Service of Canada, the union representing those scientists. The federal information commissioner is currently investigating similar complaints.

One departmental official recently warned a fisheries expert against publicly discussing a research paper, Corbett said. Many scientists are afraid to return phone calls from reporters or to discuss their publicly funded projects even if they are not specifically forbidden to do so, because of the general "chill" the federal government has imposed, Corbett added. "They want to maintain their livelihoods," he said.

But Scott Findlay, an associate professor of biology at the University of Ottawa, suggested scientists also have a responsibility to the public to take a more "proactive" attitude in speaking out, "so we are able to do what the public expects of us." - Laura Eggertson, CMAJ.

CMAJ 2013. DOI:10.1503/cmaj.109-4606 